\section{Adjustments of visual tilt as a function of age*}

\author{
FRANCES C. VOLKMANN† and PETER B. PUFALL \\ Smith College, Northampton, Massachusetts 01060
}

Using a psychophysical method of adjustment, $175 \mathrm{Ss}$, ranging in age from 3 to 20 years, made four adjustments each of a luminous line to subjective vertical, horizontal, and 45-deg tilts in the dark. There were no significant differences in mean errors of adjustment to the vertical and horizontal over the ages tested. There were significant differences in intra-S variability of adjustment to the horizontal and vertical, with the greatest improvement occurring before age 10 . Older children and adults produced significantly larger mean errors of adjustment to the 45-deg tilt than did the younger children; but the variability of settings by younger children was very high, indicating that they did not discriminate the 45-deg tilt more accurately than the older groups. The intra-S variability at all ages showed that adjustment was more accurate to the horizontal and vertical than to the 45-deg tilt.

The human visual system is well equipped to abstract properties of shape and contour of a stimulus, even though the stimulus is displaced laterally or in depth, is tilted, or is moved over the visual field. These other variables are also abstracted, however, and appear to be of similar importance in sensory coding (see Dodwell, 1970). A comparative and developmental approach to the study of these variables is already beginning to yield interesting possibilities concerning the functional organization of visual systems and of behavioral response systems. To take stimulus tilt, or orientation, as an example, data are available from such fields as neurophysiology, systems engineering, and human and animal psychophysics.

\section{Animal Studies}

In neurophysiology, such workers as Hubel and Wiesel $(1962,1965)$ have isolated cortical cells which respond selectively to stimuli of specific tilts, and whose response decreases abruptly with a change in stimulus orientation until no responding occurs to a stimulus tilted $10 \mathrm{deg}$ or so from the maximally effective tilt. These units abstract the variable of tilt, disregarding, within limits, changes in other stimulus variables such as size or location on the retina. No specific orientations of these receptive fields, such as the horizontal and vertical,

*We are indebted to the Psychology Department at Mount Holyoke College for the loan of the apparatus; to John Volkmann for his advice and support throughout the research; to Grace Craig for her statistical expertise; to Lewis P. Lipsitt for his comments on an earier form of this research conducted at Brown University; and to Dana Prizer for her help in running Ss.

+Requests for reprints should be sent to Frances C. Volkmann, Psychology Department, Clark Science Center, Smith College, Northampton, Massachusetts 01060 . have been found to predominate in the cat or the rabbit when stationary stimuli are used. Correspondingly, behavioral evidence indicates that these animals can discriminate various orientations. The correlation between neurophysiological and behavioral evidence in other species is limited, but Young (1964) has shown a predominance of horizontal and vertical orientations in optic lobe dendritic fields of octopus, and Sutherland (1957) has demonstrated that these animals can make horizontal and vertical discriminations but have difficulty in discriminating oblique lines oriented $90 \mathrm{deg}$ apart. This and additional evidence is summarized by Dodwell (1970), who raises the interesting possibility that animals in which horizontal and vertical predominate behaviorally may show a nonrandom distribution of cellular receptive fields with respect to orientation, with horizontal and vertical also predominant neurophysiologically. Whether or not this turns out to be the case, the very existence of cellular analyzers raises such questions as the following: Do these analyzers determine the range and differences in tilt which an animal can discriminate? Do they vary systematically among species? Do they change developmentally within a species, that is, do their response characteristics remain constant or can they be "tuned" as a function of age or experience? The systematic convergence of neurophysiological and behavioral data is necessary for answering such questions.

\section{Studies with Adult \\ Human Subjects}

In humans, it is necessary to rely on behavioral evidence. There is a wealth of evidence about adults, and it points to the horizontal and vertical orientations as of special importance in visual coding, in several respects :

(1) The horizontal and vertical occur as principal features in a variety of visual discriminations. In the estimation or production of tilts (Gibson \& Radner, 1937; Reese, Reese, Volkmann, \& Corbin, 1953; Leibowitz, Myers, \& Grant, 1955), in the setting of one line parallel to another (Takala, 1951; Rochlin, 1955) or perpendicular to another (Onley \& Volkmann, 1958); in vernier acuity (Leibowitz, 1953) and the threshold acuity for the width of thin wires (Baker, 1958; Ogilvie \& Taylor, 1958) even in the recognition of forms (Rock, 1956; Rock \& Heimer, 1957), it turns out that sensory performance is more accurate at the horizontal and vertical than at other tilts (see also Taylor, 1963; Howard \& Templeton 1966).

(2) The horizontal and vertical are themselves discriminated with higher accuracy than are other orientations. Among the experiments which have measured the accuracy of setting a line of light to the horizontal and vertical in the dark, Jastrow (1892), Neal (1926), Mann, Berthelot-Berry, and Dauterive (1949), and Reese et al (1953) all found mean errors of adjustment to the vertical to be less than 1.0 deg of arc; Witkin and Asch (1948) found a mean error of $1.5 \mathrm{deg}$. Comparably small mean errors have been found for the horizontal.

(3) In a series of experiments conducted at Mount Holyoke College under a variety of viewing conditions, Reese et al (1953) found that both estimation and adjustment were most accurate and most consistent in the region of the vertical and horizontal. In some experiments, a secondary increase in accuracy was found at the 45-deg tilt, but in others this was not the case (Muller, Sidorsky, Slivinske, Alluisi, \& Fitts, 1955). The Mount Holyoke workers concluded that the horizontal and vertical act, for adults, as natural anchoring agents whenever tilt is an experimental variable. The anchoring effects are independent of the specific stimuli presented, the instructions of the $E$, and the viewing conditions used. The 45-deg tilt was termed a derived anchoring agent, because it was regarded as a subjective bisection of the angle between the horizontal and vertical, and because it was not always apparent.

Much earlier, Jastrow (1892) had concluded that we carry the horizontal and vertical coordinates around in our heads - that they are innate-and that we make other discriminations on the basis of them. Neal (1926) supported this view. Others, however, have held that these discriminations are developed and refined as a by-product 
Table 1

Number of $\mathrm{Ss}_{\mathrm{s}}$ at Each CA Level Tested

CA at Last Birthday

\begin{tabular}{rrrrrrr}
3 & 4 & 5 & 6 & 8 & 10 & 20 \\
15 & 15 & 20 & 35 & 35 & 20 & 35 \\
\hline
\end{tabular}

of formal education, or as a result of sustained exposure to a physical space where horizontals and verticals may predominate. One source of evidence relevant to this question is the study of these discriminations in young children, who have not yet had any formal education or, indeed, many long years of exposure to these tilts. Ideally, one would wish to obtain experimental data on the discrimination in infants. Although those data are not available, there is some related information on children.

\section{Studies with Children}

The developmental literature has focused primarily on discrimination learning (Rudel \& Teuber, 1963; Huttenlocher, 1967a, b; Jeffrey, 1966) and on the effects of orientation on object recognition (Ghent \& Bernstein, 1961; Gibson, Gibson, Pick, \& Osser, 1962; Wohlwill \& Wiener, 1964) rather than on tilt discrimination per se. These studies indicate that orientation in the horizontal and vertical facilitate both learning and recognition processes. When lines or objects are oriented obliquely but remain $90 \mathrm{deg}$ apart, preschool-age children perform poorly or even fail to make appropriate discriminations. Perhaps the fact that each oblique is the mirror image of the other interferes with discrimination. While Rudel and Teuber (1963) have concluded that this latter discrimination problem is a function of maturation, Jeffrey (1966) and Stoddard (1968) have demonstrated that preschool-age children can learn the discrimination in special training situations. All studies agree, nevertheless, that discrimination between two oblique lines is more difficult than between a horizontal and vertical.

The above experiments with children were conducted in lighted conditions in which the main lines of the visual field were present. Most experiments conducted in darkness have been concerned with the ability of $S$ to judge the visual vertical in the presence of conflicting stimuli such as bodily tilt (Witkin, Lewis, Hertzman, Machover, Meisser, \& Wapner, 1954; Wapner \& Werner, 1957; Liebert \& Rudel, 1959; Wapner, 1968; Day \& Wade, 1969). Typically, however, these studies show high accuracy in mean adjustment of a luminous rod to the vertical by erect Ss. The Clark group found no developmental trend in mean errors among Ss ranging in age from 7 to 17 years (Wapner, 1968).
Differences in variability have been discussed mainly in terms of "starting position effect," in which the child's adjustment to the vertical is actually tilted in the direction in which the rod was offset at the beginning of a trial. These effects decrease with age between 7 and 19 years (Comalli, Wapner, \& Werner, 1959; Wohlwill, 1960).

Two studies that are more directly related to tilt discrimination per se support the findings from comparative and adult research. Olson (1968) observed that 3- to 5-year-old children had difficulty in copying diagonals (45-deg orientations) but not horizontals and verticals. Würsten (1947) found with young children, as others have with adults, that it is easier to judge lines as parallel when in the vertical or horizontal as compared to when they are obliquely oriented.

Apparently, the only experiment which actually measured the discrimination of the horizontal and vertical in the dark by preschool children was conducted by the Mount Holyoke workers (Reese et al, 1953). Ten nursery school children, 3-6 years of age, made 10 settings each to the horizontal and to the vertical, and produced a mean error of less than $1.0 \mathrm{deg}$ in both cases. Standard deviations were about $0.85 \mathrm{deg}$ for the horizontal and $1.5 \mathrm{deg}$ for the vertical. These data indicate that young children make this discrimination very accurately. They suggest that a useful next experiment might include (1) an even finer breakdown of ages, especially during the preschool period when developmental changes are rapid, (2) the inclusion of adults, and (3) the inclusion of the 45-deg tilt, all using the same psychophysical method. The present experiment thus aims at determining the accuracy and variability of adjustments of a line of light to the horizontal, vertical, and
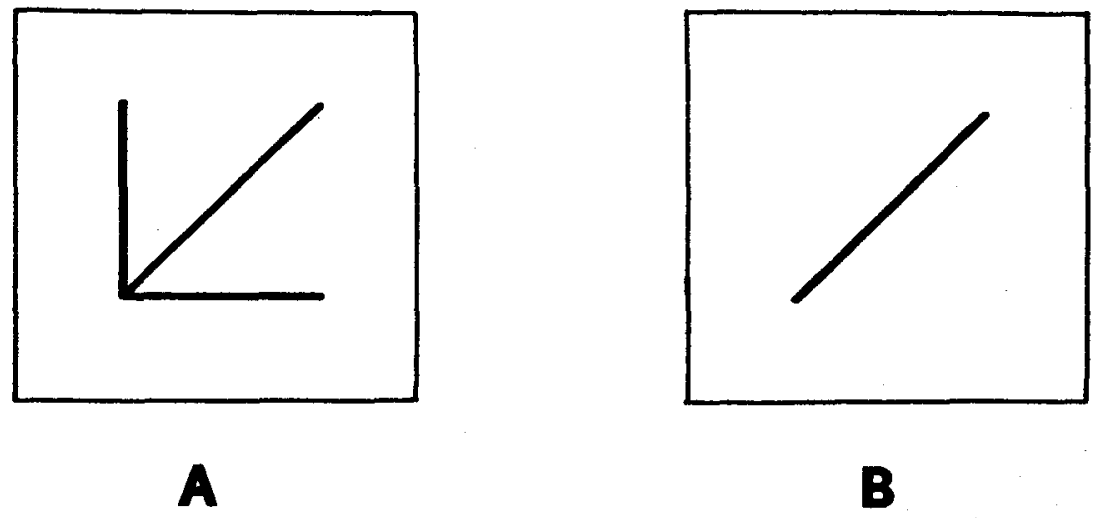

Fig. 1. Representations of the stimulus cards (A and B) used to instruct children on the 45-deg adjustment. See text for explanation. 45-deg tilts in the dark, for human Ss ranging in age from very young children to adults.

\section{METHOD \\ Subjects}

The experiment employed $175 \mathrm{Ss}$ in seven age groups. The number of $\mathrm{Ss}$ in each age group is reported in Table 1. Children in the first six groups attended the Smith College Preschool public schools. They came one at a time to a quiet room in the school building during class time to serve in the experiment. Ss in the adult (age 20) group were volunteers from psychology courses at Smith College. The two sexes were about equally represented in the children's groups (see Bauermeister, Wapner, \& Werner, 1963); all of the adult Ss were women.

\section{Apparatus}

The experiment required apparatus that would (1) block out all of the S's visual field, (2) present a thin line of light, the tilt of which could be varied by either the $S$ or the $E$, (3) permit accurate and rapid measurements of the tilt of the stimulus line, and (4) provide an appropriate, comfortable, and nonanxietyproducing means of obtaining data from $S s$ whose ages and capabilities span a wide range. A historical piece of psychophysical equipment met these requirements: it consisted of the stimulus line used by Neal in 1926 , later mounted in a long black box, and renovated for the present study. which was $180 \mathrm{~cm}$ long $\times 40 \mathrm{~cm}$ square. A padded chinrest and forehead bar aided in stabilizing his head in the upright position. A black cloth covered his head, and the inside of the box was completely black, eliminating all reference points in the S's visual field. the Smith College Day School, or local

(1) The $S$ sat at one end of the box, 


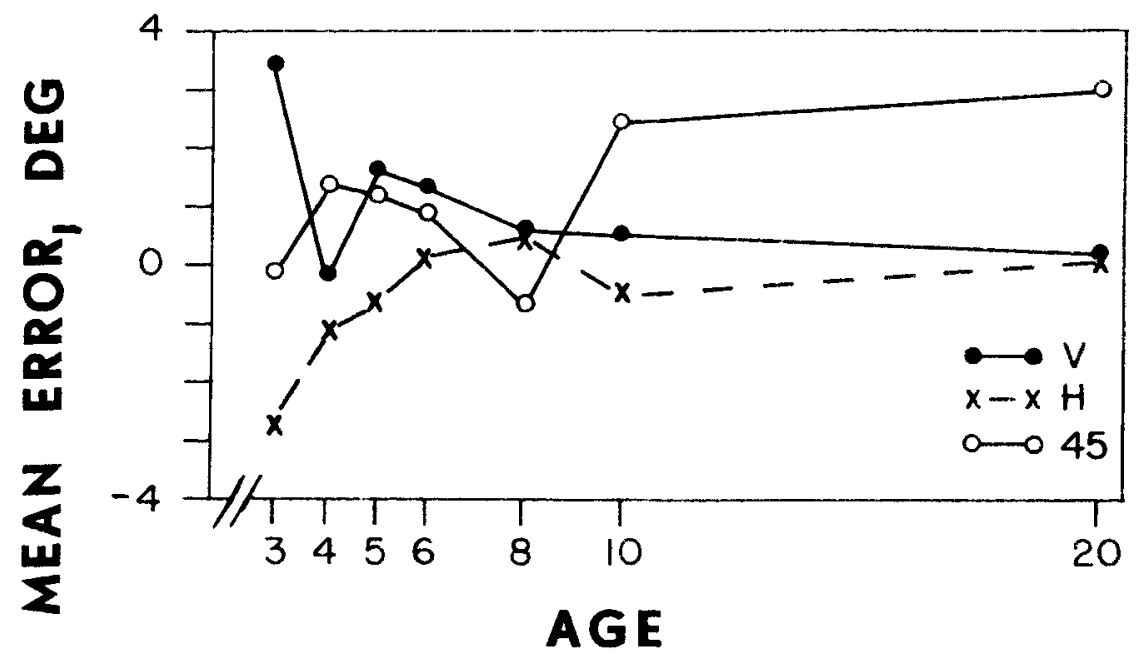

Fig. 2. Mean errors of adjustment for each tilt as a function of age. Positive numbers indicate errors in a clockwise direction; negative numbers indicate errors in a counterclockwise direction with respect to objective tilt.

(2) The stimulus appeared at the opposite end of the box, and consisted of a line of orange light of approximately $0.11 \mathrm{fL}$ luminance, as measured from the $S$ 's position. The line of light measured $1 \mathrm{~mm} \times 10 \mathrm{~cm}$, and was produced by two $3-\mathrm{W}$ neon lamps. These lamps were mounted about $6 \mathrm{~cm}$ apart along the axis of a $1 \mathrm{~mm} \times 10 \mathrm{~cm}$ slit cut along the diameter in one end of a cylinder and 8 in. behind the slit. Milkglass mounted between the slit and the lamps produced homogeneous illumination of the slit. At the other end of the closed cylinder, an axially mounted shaft extended through the end of the box. This shaft was, in turn, connected through a bead chain and sprocket system to a second, driving, shaft located at one side of the box. This driving shaft extended the entire length of the box and had a knob attached at either end, so that the $S$ or the $E$ could adjust the tilt of the line of light. When the knobs were turned, the line rotated around its center. Turning the line through $360 \mathrm{deg}$ required 40 complete revolutions of the S's knob.

(3) A long pointer was attached outside the box to the shaft which rotated the stimulus line. As the line rotated, the pointer moved over an enlarged scale ( $r=15$ in.) which could be read to $0.1 \mathrm{deg}$ of arc. The apparatus was calibrated at the vertical by means of a plumb line and at the horizontal by an accurate machinist's level. The 45-deg calibration required a bisection of the horizontal and vertical. These calibrations proved to be accurate and stable over several checks made during the course of the experiment.

(4) The driving shaft operated the $S$ was seated at the apparatus, the $E$ pointed out the stimulus line and adjustment. indicated how it could be rotated by turning the S's knob. The child then turned the knob himself in either direction for a short time.

Next, the $E$ showed the $S$ several white lines, similar in size to the stimulus line, which were drawn at different tilts on 11-in. squares of black cardboard. She pointed out which lines were "straight up and down," and then asked the child to designate other vertically oriented lines in contrast to tilted lines. When the $S$ appeared to understand this task, the $E$ instructed him to "watch the line in the box and turn the knob until the line is exactly straight up and down, then tell me." After the adjustment was made and recorded, the $E$ turned the line off the vertical by more than $15 \mathrm{deg}$. This initial offset was balanced between the clockwise and counterclockwise directions in successive trials, and the magnitude of the offset was varied over a wide range. Starting position effects were minimized by permitting the child to rotate the stimulus line back and forth as much as he wished in making each adjustment. The $S$ repeated the adjustment until he had made a total of four settings.

A similar procedure was used for horizontal adjustments. This time the $S$ picked out lines which were "flat like the table" in the pretraining task, and set the stimulus line to be "just as flat as you can make it."

Instructions to adjust the line to the 45-deg inclination were more difficult. The $\mathbf{S}$ was first shown the lines which appear in Card A, Fig. 1. Designating the vertical and horizontal lines, the $E$ pointed out that "you already made

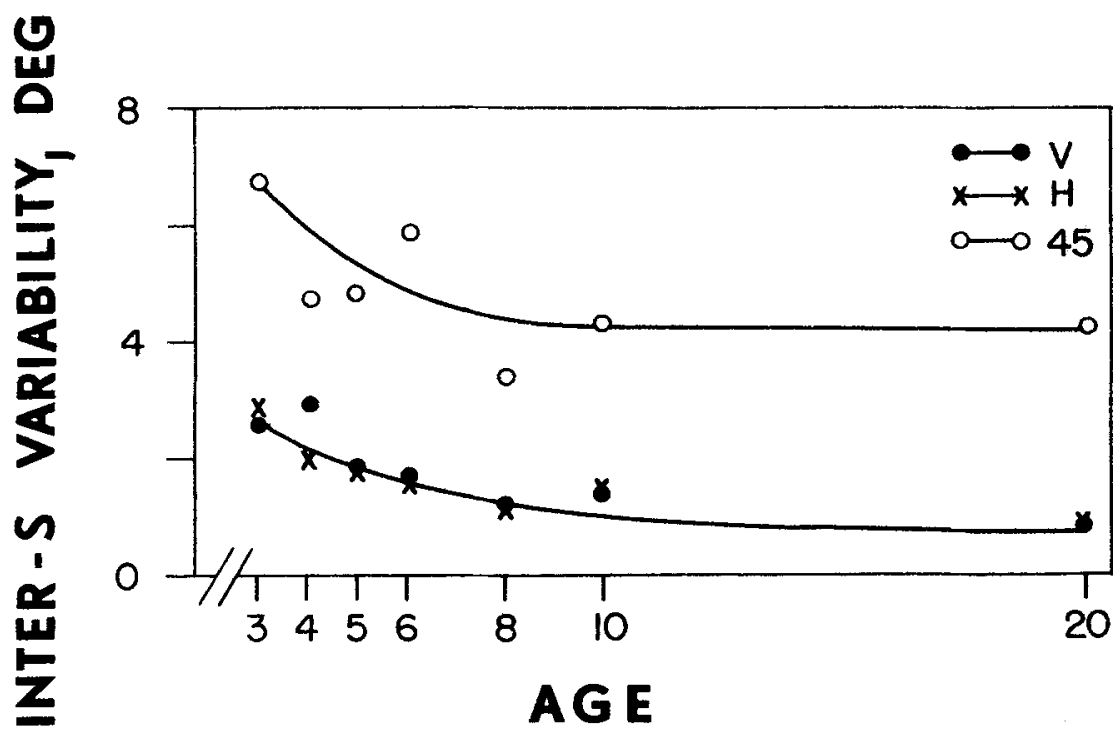

Fig. 3. Inter-S variability for each tilt as a function of age. Variability is expressed in terms of standard deviations calculated from mian errors of 
the line straight up and down like this, and flat like this, didn't you? Now I want you to make the line crisscross like this one (pointing to the 45-deg line), right in between the other two." She emphasized that it was exactly the 45-deg line that was required, and not any other tilt. Finally the child was shown the 45-deg line alone, as shown on Card B, Fig. 1. He made the adjustment in the same way as for the vertical and horizontal described above.

Procedure for adults. Each $\mathbf{S}$ was seated at the apparatus and shown the stimulus line and the control knob. The adult $S$ received only verbal instructions, after which she made four adjustments each to the vertical and horizontal, followed by four adjustments to the $45-\mathrm{deg}$ position, in exactly the same way as did the children.

The experiment thus employed a standard psychophysical method, that of adjustment, which did not have to be modified at all for use with young children. The only modification necessary was in instructions, where the terms "vertical" and "horizontal" were changed to "straight up and down" and "flat like the table," and where cards were used to demonstrate pictorially what was required of the S.

\section{RESULTS}

The accuracy with which each $S$ set the line to the specified orientations, and the variability of the settings provided the basic data of the experiment. A mean error of adjustment was calculated for each $S$ for each orientation; group mean errors were then derived from the individual means. A standard deviation was also calculated for each $\mathrm{S}$ for each orientation as a measure of the variability of an individual's adjustments. Statistical analyses of these two dependent measures consisted of a split-plot analysis of variance with age and orientation as the main effects. Since the numbers of Ss were unequal in the various groups, a least squares analysis of variance was used.

Mean Errors of Adjustment

Figure 2 shows the mean errors of adjustment as a function of age for the three orientations. Analysis showed no significant age effect $(F=1.955$; $\mathrm{df}=6,168$ ) but a significant effect due to orientation $(\mathrm{F}=18.466 ; \mathrm{df}=2,336$; $\mathrm{p}<.001$ ). Due to the significant Age by Orientation interaction $(F=3.898$; $\mathrm{df}=12,336 ; \mathrm{p}<.001$ ), analyses of simple effects were performed. 1 The only significant age effect was for the 45 -deg orientation $(F=5.09$; $\mathrm{df}=6,168 ; \mathrm{p}<.01$ ). Two of the seven analyses of the simple effects of

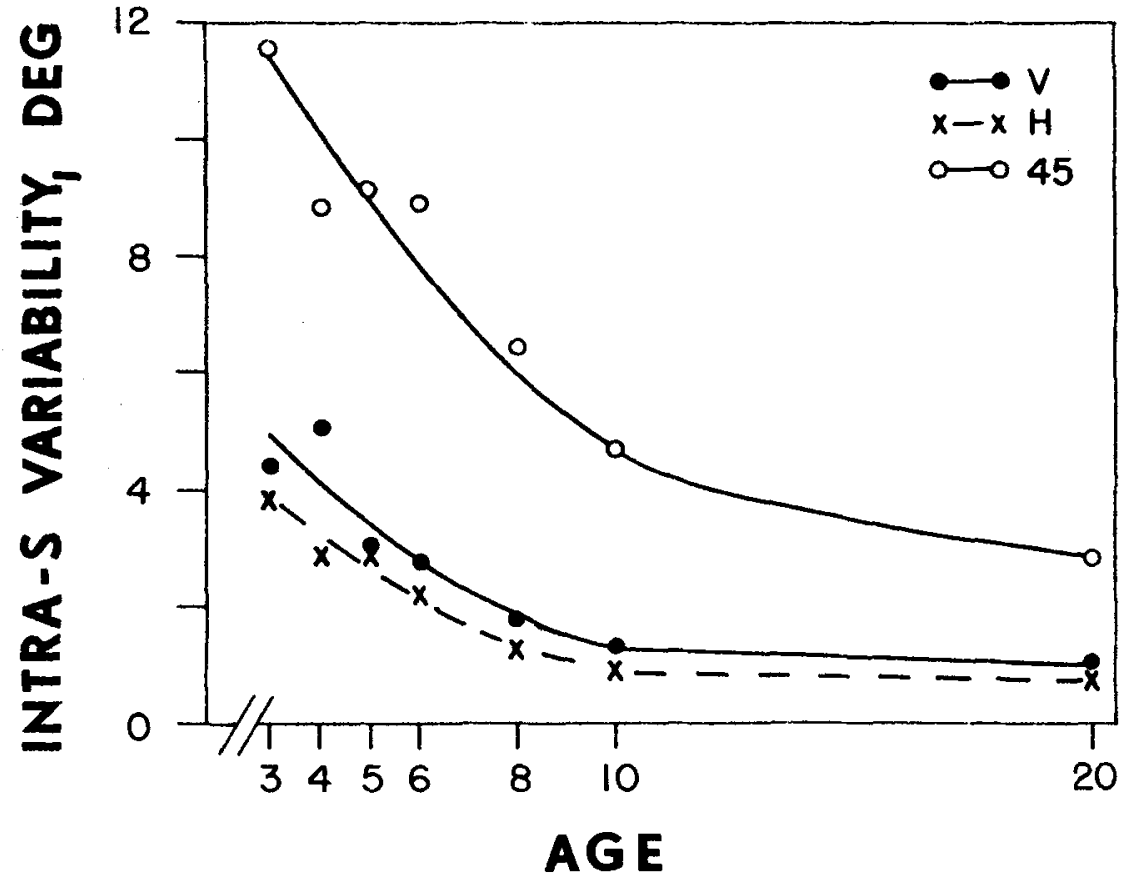

Fig. 4. Intra-S variability for each tilt as a function of age. Variability is expressed in terms of standard deviations calculated from the adjustments made by each $\mathrm{S}$ to each tilt, and corrected for sampling bias (Hayes, 1963).

orientation were significant, at age 3 $(\mathrm{F}=15.07 ; \mathrm{df}=2,336 ; \mathrm{p}<.01) ;$ the analyses at age 10 approached significance.

These effects appear in Fig. 2; at the younger ages the mean errors are clockwise at the vertical and counterclockwise at the horizontal, with both errors decreasing with increasing age. The fact that the age effect was not significant and that the only significant difference among orientations occurred at age 3 indicates that the children improved substantially between 3 and 4 years in accuracy of adjusting to the vertical and horizontal. An unpredicted and significant decrease in accuracy of adjustment to the $45-\mathrm{deg}$ tilt occurred with increasing age. For the three younger groups, the mean error was approximately zero $(0.47 \mathrm{deg})$, while at ages 10 and 20 the mean errors were 2.50 and $3.02 \mathrm{deg}$, respectively. The effect appears as a marked difference between the younger Ss (ages 3 to 8 years) and the older ones (ages 10 or adult) and not as a gradual trend. An examination of the intra-S variability clarifies this anomalous finding somewhat (see also the last paragraph of Discussion).

Figure 3, inter-S variability as a function of age, indicates the degree of variability among $S s$ in terms of their mean settings to each specified orientation. Variability is low for settings to the vertical and horizontal for all ages; at age 3, two-thirds of the individual mean errors fall within $\pm 3 \mathrm{deg}$ of the group mean error; at age 20 , two-thirds fall within $\pm 1 \mathrm{deg}$ of the group mean error (an error of $<1$ deg indicates that the ends of the stimulus line departed from zero error by less than 0.035 in.). By contrast, the variability among $\mathrm{Ss}$ is high for settings to the 45-deg tilt. The data suggest a small decrease in this variability with increasing age, but even adult Ss varied more in their mean adjustments to the 45-deg tilt than 3-year-olds did in their settings to the horizontal and vertical.

\section{Variability of}

Individual Adjustments

The consistency with which each $S$ made successive settings to a given orientation appears in Fig. 4, which shows intra-S variability as a function of age. The analysis of variance shows a significant effect of age $(F=32.43$; $\mathrm{d} f=6,168 ; p<.001)$ and of orientation $(F=251.41 ; \mathrm{df}=2,336$ $\mathrm{p}<.001)$ and a significant interaction between them ( $F=5.911$; $\mathrm{df}=12,336 ; \mathrm{p}<.001$ ). Since the interaction was significant, analyses of simple effects were performed. The age effect was significant for both vertical and 45-deg orientations $(\mathrm{F}=4.57 ;$ df $=6,168 ; \mathrm{p}<.01$, and $F=36.19 ; \quad d f=6,168 ; \quad p<.001$, respectively), and approached significance for the horizontal orientation $(F=2.58 ; \quad d f=6,168$; $p<.025)$. The analyses of the effects 
of orientations for all ages reached at least the $p<.01$ level of significance.

Figure 4 shows a consistent trend toward lower variability with increasing age, with the variability of the horizontal and vertical adjustments parallel to but substantially smaller than that for the 45-deg adjustments. The interaction is due to the fact that the differences between the 45-deg tilt and the vertical and horizontal diminishes with increasing age. Finally, it is interesting to note that the intraand inter-S variability scores parallel each other; there is marked variability in adjustments to the 45-deg tilt which, though it diminishes with age, is still appreciable by age 20 . By contrast, variability in adjustments to the horizontal and vertical is small at all ages tested, and approaches zero for the 10- and 20-year-old Ss.

\section{DISCUSSION}

The Discrimination of

Horizontal and Vertical

It is clear that the discrimination of horizontal and vertical is already reasonably well developed in preschool children. In the present experiment, there was no significant decrease in mean error of adjustment to these orientations as a function of age. This finding confirms and extends those of the Mount Holyoke College and Clark University workers (Reese et al, 1953; Wapner, 1968), and is consistent with other findings (see Introduction) which suggest innate coding of the horizontal and vertical orientations in the visual system. An alternative explanation is that the discrimination develops in children as a result of experience in a world where horizontals and verticals are redundantly supplied and predominate statistically. This latter explanation, though not ruled out for humans, does not fit well with either the neurophysiological or the comparative findings. If humans acquire the discriminations, it must be at a very early age. Perhaps these discriminations are made by the time the child sits, or certainly by the time he walks; it is difficult to understand how the posturing and locomotor behavior involved in sitting and walking could develop without the discrimination of vertical and horizontal, or at least of a stable ground plane.

On the other hand, discrimination is not perfect in the youngest children; there is significant improvement from age 3 to age 4 years, with continued, though not statistically significant improvement thereafter. The mean errors of adjustment for vertical tend to be clockwise and those for horizontal tend to be counterclockwise at the younger ages; thus, the sizes of the subjective quadrants of tilt might be thought of as unequal, with the first and third quadrants subtending an angle of less than $90 \mathrm{deg}$ and the second and fourth subtending an angle of greater than 90 deg. ${ }^{2}$ With increasing age, the subjective tilts approximate the objective tilts (0.09- and 0.17-deg errors at age 20 ) and the remaining small errors tend to be clockwise for both orientations, thus achieving equality of quadrant size. These latter findings replicate those of Reese et al (1953) for adults and extend them to children down to at least 8 years of age.

The most reliable developmental effect, however, is the small but significant decrease in intra-s variability as a function of age. The gradual reduction of variability may be due to improved perceptual-motor coordination which, with age, would mediate better performance in this experimental situation. One may wish to think of the improvement as a change with age in the child's operating characteristic or in his confidence criterion. Young children make their adjustments very rapidly; they turn the knob a few times and quit. Older children and adults, on the other hand, take a longer time; they "home in" on the adjustment and make a larger number of very small changes in the tilt of the line. The improvement must occur fairly early, however; by 8 years, the present children approximated adult discriminatory behavior on the horizontal and vertical, in terms of both central tendency and variability.

Discrimination of the 45-deg Tilt

Results for the 45-deg tilt contrast sharply with those on the horizontal and vertical. They agree with other evidence reviewed in the introduction which suggests that the horizontal and vertical are primary and the $45-\mathrm{deg}$ tilt secondary in humans. The 10-year-old children and adults actually make significantly greater mean errors of adjustment than the younger children, a result which is made even more impressive by a concurrent decrease in the variability of adjustments by the two older groups. Such a developmental discontinuity does not appear to have been observed previously, although Wohlwill (1960, 1963) has noted a shift from under- to overconstancy in size and distance judgments at around 7 or 8 years. He suggests that this shift is not a function of the discrimination of new perceptual information but rather of the child's deliberate effort to coordinate the perceptual information he already has. A similar explanation for the present results can be derived from Piaget's theory of the development of spatial concepts (Piaget \& Inhelder, 1956; Piaget, Inhelder, \& Szeminska, 1960), which argues that vertical and horizontal must be organized into a reference system before the child begins to try to construct accurate angular relations. Such an explanation is only one of several possibilities, indicating that more information is needed relevant to the process by which the $45-\mathrm{deg}$ tilt is determined and whether or not that process changes with age.

The small mean errors of adjustment to the $45-\mathrm{deg}$ position for very young children may well be artifactual, given the large intra-S variability. Consider the following possibility: Let us assume that (1) adjustments to the 45-deg position are strictly limited by the vertical and horizontal planes which bound the quadrant; (2) at very early ages, adjustments to the $45-\mathrm{deg}$ position are made "at random" between these boundaries; (3) "at random" is defined as plus or minus 3 SD on a normal distribution. It follows that at these early ages, the intra-S variability will approximate $1 / 6(\mathrm{H}-\mathrm{V})=1 / 6(90 \mathrm{deg})$ $=15$ deg. Examination of Fig. 4 tends to support such assumptions; 3 in any event, one would not conclude that the young children were accurate at this task. They frequently had trouble performing it, and many who were happy to set the line "straight up and down" or "flat like the table" verbalized that "I don't like this game," or "This is too hard," when they were asked to make the $45-\mathrm{deg}$ adjustment.

BAKER, C REFERENCES

ONR Symposium Report Physiological Psychology, U.S. Naval School of Aviation Medicine, Pensacola, Florida, 1958, p. 134 .

BAUERMEISTER, M., WAPNER, S \& WERNER, H. Sex differences in the perception of apparent verticality and apparent body position under conditions of body tilt. Joumal of Personality, 1963, 31, 394-407.

COM ALLI, P. E., WAPNER, S. \& WERNER, H. Perception of verticality in middle and old age. Joumal of Psychology, 1959, 47, 259-266.

DAY, R. H., WADE, N. J. Mechanisms involved in visual orientation constancy. Psychological Bulletin, 1969, 71, 33-42. DODWELL, P. C. Visual pattern recognition. New York: Holt, Rinehart, \& Winston, 1970.

GHENT, L., \& BERNSTEIN, L. Influence of the orientation of geometric forms on their recognition by children. Perceptual \& Motor Skills, 1961, 12, 95-101.

GIBSON, E. J., GIBSON, J. J., PICK, A. D., \& OSSER, H. A developmental study of the discriminability of letter-like forms. Journal of Comparative \& Physiological Psychology, 1962, 55, 897-906.

GIBSON, J. J., \& RADNER, M. Adaptation, after-effect, and contrast in the perception of tilted lines. I. Quantitative studies. Journal of Experimental Psychology, 1937, 20, 453-467. 
HAYS, W. L. Statistics for psychologists. New York: Holt, Rinehart, \& Winston, 1963. P. 210 (formula 7.16.6).

HOWARD, I. P.. \& TEMPLETON, W. B Human spatial orientation. New York: Wiley, 1966 .

HUBEL, D. H., \& WIESEL, T. N. Receptive fields, binocular interaction and functional architecture in the cat's visual cortex. Journal of Physiology, 1962, 160. 106-154.

HUBEL, D. H., \& WIESEL, T. N. Receptive fields and functional architecture in two non-striate visual areas (18 and 19) of the cat. Journal of Neurophysiology, 1965 . 28, 229-289.

HUTTENLOCHER, J. Discrimination of figure orientation: Effects of relative position. Journal of Comparative \& Physiological Psychology, 1967a, 63, 359-361.

HUTTENLOCHER, J. Children's ability to order and orient objects. Child Development, 1967b, 38, 1169-1176.

JASTROW, J. On the judgment of angles and the positions of lines. American Journal of Psychology, 1892, 5, 214-223.

JEFFREY, W. E. Discrimination of oblique lines by children. Journal of Comparative \& Physiological Psychology, 1966, 62. $154-156$.

LEIBOWITZ, H. Some observations and theory on the variation of visual acuity with the orientation of the test object. Journal of the Optical Society of America, 1953, 43, 902-905.

LEIBOWITZ, H., MYERS, N. A., \& GRANT, D. A. Radial localization of a single stimulus as a function of luminance and duration of exposure. Joumal of the Optical Society of America, 1955, 45 76-86.

LIEBERT, R. S., \& RUDEL, R. G. Auditory localization and adaptation to body tilt A developmental study Child Development, 1959, 30, 81-91.

MANN, C. W, BERTHELOT-BERRY, N H., \& DAUTERIVE, H. J. The perception of the vertical: 1. Visual and non-labyrinthine cues. Journal of Experimental Psychology, 1949, 39, 538-547.

MULLER, P. F., SIDORSKY, R. C, SLIVINSKE, A. J., ALLUISI, E. A., \& FITTS, P. M. The symbolic coding of information on cathode ray tubes and similar displays. USAF WADC Technical Report No. 55-375, 1955.

NEAL, E. Visual localization of the vertical American Journal of Psychology, 1926 37, 287-291.

OGILVIE, J. C, \& TAYLOR, M. M. Effects of orientation on the visibility of fine wires. Journal of the Optical Society of America, 1958, 48,628-629.

OLSON, D. R. From perceiving to performing the diagonal. Ontario Journal of Educational Research, 1968, 10 , 171-179.

ONLEY, J., \& VOLKMANN, J. The visual perception of perpendicularity. American Journal of Psychology, 1958, 71 . 504-516.

PIAGET, J., \& INHELDER, B. The child's conception of space. London: Routledge \& Kegan Paul, 1956.

P I A GET, J., I NHELDER, B. \& \& SZEMINSKA, A. The child's conception of geometry. New York: Harper Torchbooks, 1960

REESE, E. P., REESE, T. W, VOLKMANN, J. \& CORBIN, H. H. Psychophysical Research Summary Report, 1946-1952. NAVEXOS P-1104, Special Devices Center. Technical Report No. SDC-131-1-5, 1953, 9-29.

ROCHLIN. A. M. The effect of tilt on the visual perception of parallelism. American Journal of Psychology, 1955, 68, 223-236

ROCK, I. The orientation of forms on the retina and in the environment. American Journal of Psychology, 1956, 69, 513-528.

ROCK, I., \& HEIMER, W. The effect of retinal and phenomenal orientation on the perception of form. American Journal of Psychology, 1957, 70, 493-511.

RUDEL , R . G., \& TEUBER, H Discrimination of dixection of line in children. Journal of Comparative \& Physiological Psychology, 1963, 56. $892-898$.

STODDARD, $\mathrm{L}$, L. An observation on stimulus control in a tilt discrimination by children. Journal of the Experimental Analysis of Behavior, 1968, $11,321-324$.

SUTHERLAND, N. S. Visual discrimination of orientation by octopus. British Journal of Psychology, 1957, 48, 55-70.

TAKALA, $M$. On constant errors in the judgment of the degree of inclinations. Acta Psychologica Fennicus, 1951, 1, 129-142.

TAYLOR. M. M. Visual discrimination and orientation. Journal of the Optical Society of America, 1963, 53, 763-765. WAPNER, S. Age changes in perception of verticality and of the longitudinal body axis under body tilt. Joumal of Experimental Child Psychology, 1968, 6, 543-555.

WAPNER, S., \& WERNER, H. Perceptual development: An investigation within the framework of sensory-tonic field theory. Worcester, Mass: Clark University Press, 1957.

WINER, B. $J_{n}$ Statistical principles in experimental design. New York: McGraw-Hill, 1962 .

WITKIN, H. A., \& ASCH, S. E. Studies in space orientation: III. Perception of the upright in the absence of a visual field.
Journal of Experimental Psychology $1948,38,603-614$

WI TKIN, H. S., LEWIS, H. B. HERTZMAN, M., MACHOVER, K. MEISSNER, P. B., \& WAPNER, S Personality through perception: An experimental and clinical study. New York: Harper, 1954.

WOHLWILL, J. F. Developmental studies of perception. Psy chological Bulletin, 1960 $57,250-288$

WOHLWILI, J. F. The development of "overconstancy" in space perception. In L. P. Lipsitt and C. C. Spiker (Eds.). Advances in child development and behavior. Vol. 1. New York: Academic Press, 1963. Pp. 266-312.

WOHLWILL, J. F., \& WIENER, M. Discrimination of form orientation in young children. Child Development, 1964, 35, $1113-1125$.

WURSTEN, H. Recherches sur le développement des perceptions: IX L'évolution des comparisons de longuers de l'enfant à l'adulte avec variation d'angle entre la verticale et l'horizontale. Archives de Psychologie, Genève, 1947. 32, 1-144.

YOUNG, J. Z. A model of the brain. Ox ford: Clarendon Press, 1964.

NOTES

1 The error terms for all simple effect were pooled exror terms. This seemed justified given the large samples in many cells (Winer, 1962). Nevertheless, significance levels were set conservatively at $\mathrm{p}<.01$.

2. If these errors of adjustment were due to a "starting position effect," two additional assumptions would have to be made: (1) that it does not have symmetrical effect, otherwise the errors would approximate zero; and (2) that the direction of the effect varies for vertical and horizontal; for the formex the greater error occurred when adjustments were counterclockwise, but for the latter the greater error occurred when adjustments were clock wise. It seems more parsimonious to assume that the method of adjustment $h$ as significantly reduced the starting position effect, and that the errors indicate the subjective vertical and horizontal.

3. The discrepancies between the derived value and the actual scores are probably due to the fact that $E$ adjusted the line to and beyond $\pm 15 \mathrm{deg}$ but not to 0 and $90 \mathrm{deg}$ before each trial, therefore eliminating the more extreme scores. The fact that the younger $S$ s frequently made adjustments outside of the $\pm 15-d e g$ range seems to support the possibility that between 3 and 6 years adjustments were made "at random."

(Accepted for publication August 3, 1971.) 